All authors should seek approval to conduct research involving human or animal subjects from an independent local, regional, or national review body (e.g., ethics committee, institutional review board). They must explain the rationale for their approach and demonstrate that the local, regional, or national review body explicitly approved the doubtful aspects of the study. Approval by a responsible review body does not preclude editors from forming their own judgment whether the conduct of the research was appropriate.

When reporting experiments on animals, authors should indicate whether institutional and national standards for the care and use of laboratory animals were followed. Further guidance on animal research ethics is available from the International Association of Veterinary Editors' Consensus Author Guidelines on Animal Ethics and Welfare (https://accountablejournalism.org/ethics-codes/consensusauthor-guidelines-on-animal-ethics-and-welfare-for-editors).

When reporting experiments on human subjects in Andover House Journals, authors should indicate whether the procedures followed were in accordance with the ethical standards of the responsible committee on human experimentation (institutional and national) and with the Helsinki Declaration of 1975, and its revisions https://www.wma.net/policies-post/wma-declaration-ofhelsinki-ethical-principles-for-medical-research-involving-human-subjects. If doubt exists whether the research was conducted in accordance with the Helsinki Declaration, the authors must explain the rationale for their approach, and demonstrate that the institutional review body explicitly approved the doubtful aspects of the study. See Recommendations for the Conduct, Reporting, Editing, and Publication of Scholarly Work in Medical Journals

All investigators should ensure that the planning conduct and reporting of human research are in accordance with the Helsinki Declaration and its revisions.

\title{
Informed Consent
}

Patients have a right to privacy that should not be violated without informed consent. Identifying information, including names, initials, or hospital numbers, should not be published in written descriptions, photographs, or pedigrees unless the information is essential for scientific purposes and the patient (or parent or guardian) gives written informed consent for publication. Informed consent for this purpose requires that an identifiable patient be shown the manuscript to be published. Authors should disclose to these patients whether any potential identifiable material might be available via the Internet as well as in print after publication.

Nonessential identifying details should be omitted. Informed consent must be obtained if there is any doubt that anonymity can be maintained. For example, masking the eye region in photographs of patients is inadequate protection of anonymity. If identifying characteristics are de-identified, authors should provide assurance, and editors should so note that such changes do not distort scientific meaning.

The requirement for informed consent should be included in the journal's instructions for authors. When informed consent has been obtained, it should be indicated in the published article.

Use of the Andover House Patient Consent Form is recommended where a consent form is required for submission of a manuscript to an Andover House publication. If another consent form is to be used, for example the standard consent form used by your institution, a blank copy of this form should be submitted to the journal so that the journal can verify that it meets best practice recommendations. If the patient or relatives of a deceased patient cannot be traced and consent cannot be obtained, the case report can only be considered for publication if it is sufficiently anonymized. 
Patient consent should be written and archived with the journal, the authors, or both, as dictated by local regulations or laws. We believe, patient confidentiality is better guarded by having the author archive the consent and instead providing the journal with a written statement that attests that they have received and archived written patient consent. 